\title{
Microleakage of Glass Ionomers Temporary Restorations in Indirect Pulp Treatment: An in vitro Study
}

\author{
Olga Cortés Lillo, Antonia Alcaina Lorente*, Sonia Guzmán Pina \\ Department of Pediatric Dentistry, Dental School, University of Murcia, Spain
}

Copyright $\bigcirc 2018$ by authors, all rights reserved. Authors agree that this article remains permanently open access under the terms of the Creative Commons Attribution License 4.0 International License

\begin{abstract}
Purpose: To compare the degrees of marginal microleakage undergone by different intermediate materials used for provisional restoration in indirect pulp treatment: glass ionomers (Ketac ${ }^{\mathrm{TM}}$ Fil Plus (3M ESPE), Ketac $^{\mathrm{TM}}$ Molar Easy Mix (3M ESPE), Fuji IX ${ }^{\mathrm{TM}}$ GP (GC)) and zinc oxide eugenol. Materials and methods: Twenty young permanent premolars, extracted for orthodontic reasons, were prepared by creating Class II cavities and then divided into four groups according to the material used for pulp capping. The materials were applied following the manufacturers' instructions and stained with methylene blue at $2 \%$ to evaluate microleakage. Results: Results were evaluated applying variance analysis (ANOVA). It was found that glass ionomers showed better outcomes than zinc oxide eugenol, with Fuji IX ${ }^{\mathrm{TM}}$ GP and Ketac ${ }^{\mathrm{TM}}$ Molar Easy Mix producing the best results. Conclusion: For indirect pulp capping, glass ionomer is a favorable material for reducing one of the main causes of treatment failure - microleakage although there are differences between brands.
\end{abstract}

Keyword Glass Ionomer, Indirect Pulp Treatment, Microleakage, Pulp Therapy

\section{Introduction}

Dental caries is without doubt one of the major challenges in dentistry. Its occurrence has numerous repercussions that all exert an influence over the integrity and development of the affected tooth. The dentist's main objective is to maintain the vitality and function of the dental pulp [1]. Vital pulp therapy includes the following treatment possibilities $[1,2]$ :

- Protective bases.

- Indirect pulp treatment, in cases of deep dental cavities.
- $\quad$ Direct pulp treatment.

- Pulpotomy, in cases of pulp exposure.

When faced with a tooth showing symptoms and changes to the periapical area, it is clear that pulpectomy is the treatment of choice. But when a tooth presents deep caries, an absence of classic clinical and radiological signs, reversible pulpitis, or normal pulp and an absence of symptoms, what is the best treatment option?

For deep cavities in deciduous teeth, the indications for carrying out indirect pulp treatment or pulpotomy are the same [2]. The difference occurs when the process of caries removal leads to pulp exposure, in which case pulpotomy will be the appropriate treatment [3].

The American Academy of Pediatric Dentistry (AAPD) gives the following definitions of these treatment options [4]:

- Pulpotomy: procedure in which coronal pulp is amputated, and the remaining radicular pulp is treated with medication or electrocautery to preserve pulp health. The aim is to leave the healthy pulp intact and free from adverse clinical signs and symptoms or radiographic evidence of internal or external root resorption.

- Indirect pulp treatment (IPT): procedure whereby caries close to the pulp is left in place and covered with a biomaterial to restore the tooth and prevent microleakage. The aims of this treatment are the same as pulpotomy.

Recent advances in biomedical research have proposed the regeneration of the dentin-pulp complex by means of procedures such as indirect pulp treatment. Current research in this area is based on gaining an understanding of the molecular and cellular mechanisms that regulate dentinogenesis during the repair of dental tissues, as well as their potential for clinical exploitation [5-9].

For this reason, IPT has become a good treatment option in cases of deep caries and reversible pulp inflammation, 
providing that diagnosis is based on sufficient clinical history, clinical and radiographic examination and the tooth can be sealed with a restoration that remains free of microleakage [10-14].

This increased understanding of dental tissue repair has led to a shift in perspective so that in many cases IPT has come to be regarded as the treatment of choice in place of pulpotomy [12].

Satisfactory pulp conditions can be ensured by performing either glass ionomer caries control (GICC) or stepwise excavation.

GICC is indicated in cases with caries cavities to diagnose vitality when the tooth shows signs and symptoms of reversible pulpitis, or in case of an asymptomatic tooth with no indication that the lesion is irreversible. The technique consists of minimal and superficial removal of the infected caries followed by glass ionomer placement. After 1-3 months, providing the tooth has remained asymptomatic and shows no clinical or radiographic signs of irreversible pulpitis, definitive restoration can be carried out [2].

In the case of stepwise excavation, at the first visit, caries-affected dentin is partially eliminated to avoid pulp exposure, leaving softened tissue close to the pulp having previously placed a calcium hydroxide base with zinc oxide eugenol temporary restoration. At a second session (4-6 weeks later), the site is reopened and the caries-affected tissue is eliminated completely $[2,16,17]$. Afterwards, the definitive restoration is performed.

For many years, it was thought that the primary causes of pulp inflammation were the toxic action of dental materials. However, it has been shown that pulp inflammation is mainly related to pulp invasion by germs or toxins. In this way, the lack of a well-sealed margin around the restoration, will lead to adverse pulp responses, changes in the tooth's color, post-operative sensitivity, and recurrent caries [18].

Therefore, in cases of indirect capping in which a provisional material is placed over pulp, it is essential to consider the degree of filtration suffered by the material used, as this is a factor which will determine success or failure.

The present study was made to evaluate the degree of microleakage undergone by different intermediate materials used as a provisional material in indirect pulp treatment: three glass ionomers (Ketac ${ }^{\mathrm{TM}}$ Fil Plus, Ketac ${ }^{\mathrm{TM}}$ Molar Easy Mix and Fuji IX ${ }^{\mathrm{TM}}$ GP) compared with zinc oxide eugenol (IRM; DENTSPLY).

\section{Material and Methods}

This research was carried out in the laboratories of the Dental Clinic of the Morales Meseguer Hospital of the University of Murcia in the Department of Pediatric Dentistry.

We worked with 40 samples, obtained from twenty young permanent premolars extracted for orthodontic reasons. The inclusion criteria were the following: absence of caries, root cracks, previous restorations or previous endodontic treatment; the detritus and remaining soft tissues that may remain in the root will be eliminated with a curette; teeth that have similar root dimensions in both mesio-distal and bucco-lingual diameter will be included.

These were divided into four study groups according to the material assayed and a class II cavity was created in 2 $\mathrm{mm}$ deep, $3 \mathrm{~mm}$ high and $4 \mathrm{~mm}$ wide approximately, on the mesial and distal face of each tooth.

The materials used were Ketac ${ }^{\mathrm{TM}}$ Fil Plus (3M ESPE), Ketac $^{\text {TM }}$ Molar Easy Mix (3M ESPE), Fuji IX ${ }^{\mathrm{TM}}$ GP (GC) compared with zinc oxide eugenol (IRM,DENTSPLY).

The cavities were made with a strawberry 330 of tungsten carbide in a high speed turbine and with water and air cooling by the same operator. The capping materials were prepared following the manufacturers' instructions and obturations performed. Samples were stored in water for 24 hours after obturation.

All the pieces were varnished with two layers of nail polish at a distance of approximately $1 \mathrm{~mm}$ outside the margin of the preparation. They were placed upside down, with the cusps lightly pressed on type pink wax and with methylene blue stain at $2 \%$ until the cemento enamel junction for 24 hours, so that the dye only covered the crown. Even so, the apexes were previously sealed with Cavit TM to avoid the risk of dye penetration in that area.

The samples were sectioned longitudinally, making a cut per tooth, so that each tooth is obtained two halves with their respective classes II, being therefore 40 halves in total. The observation of the microfiltration was performed by the same operator using an Olympus SZ-CTV magnifier connected to a Sony CCD-IRIS / RGB camera and this in turn to a computer with MIP 4.5 Advance V5 image acquisition and analysis software 0.02 . Digital Imagen System S.L.

(Figure 1. Sectioned premolar obturated with Fuji IXTM GP as seen under microscope.)

(Figure 2. Section of premolar obturated with zinc oxide eugenol as seen under optical microscope.)

Each tooth was evaluated using the microleakage scale proposed by Miller et al. ${ }^{19}$, as follows (Table 1)

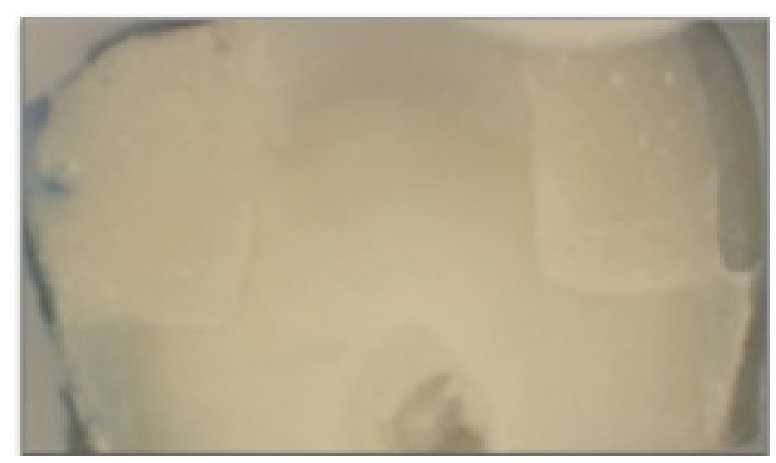

Figure 1. Sectioned premolar obturated with Fuji IX ${ }^{\mathrm{TM}} \mathrm{GP}$ as seen under microscope 


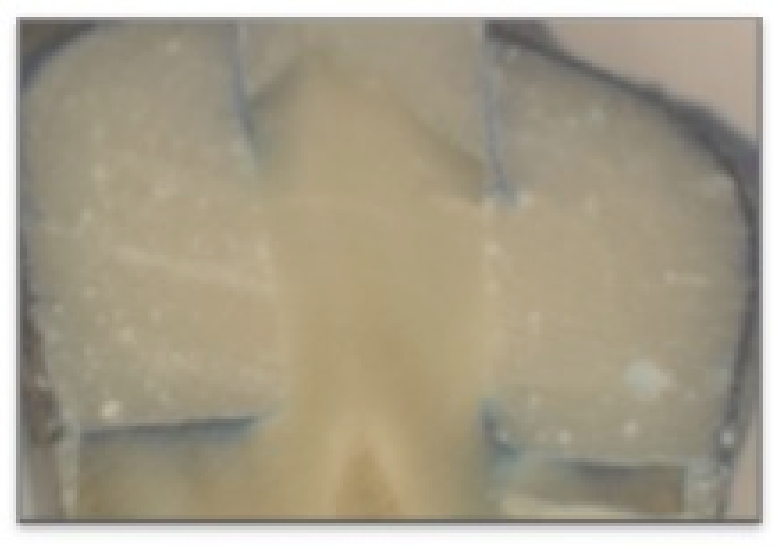

Figure 2. Section of premolar obturated with zinc oxide eugenol as seen under optical microscope

Table 1. Microfiltration scale according to stain penetration

\begin{tabular}{|c|c|}
\hline LEVEL & OBSERVATION \\
\hline 0 & No penetration by the colored stain \\
\hline 1 & $\begin{array}{c}\text { Stain penetration up to half of the gingival (or axial) } \\
\text { wall }\end{array}$ \\
\hline 2 & $\begin{array}{c}\text { Stain penetration exceeding half of the gingival (or } \\
\text { axial) wall }\end{array}$ \\
\hline 3 & Stain penetration along entire gingival wall \\
\hline
\end{tabular}

\section{Results}

One-factor variance analysis (ANOVA) identified statistically significant differences in microleakage between the different materials assayed. On the basis of the microleakage criteria established, it was found that glass ionomers showed the most favorable results in comparison with teeth obturated with zinc oxide eugenol. (Figures 1 \& 2) In particular, Fuji IX $\mathrm{X}^{\mathrm{TM}}$ and GP Ketac ${ }^{\mathrm{TM}}$ Molar Easy Mix produced the best results. (Graph 1)

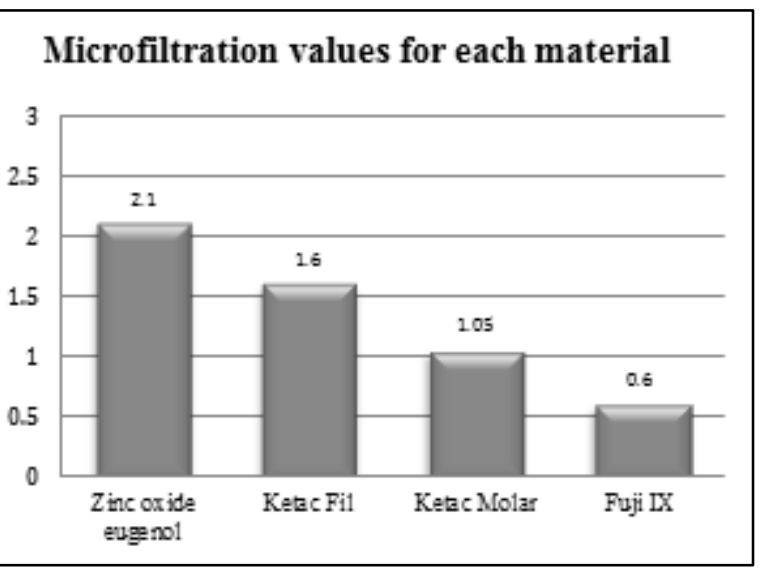

Graph 1. Microfiltration values according to material used for obturation.

In relation to microleakage differences between walls (gingival or axial), Fuji IX ${ }^{\mathrm{TM}}$ showed lower values on the gingival wall, while the other materials underwent less microleakage on the axial wall. (Graph 2)

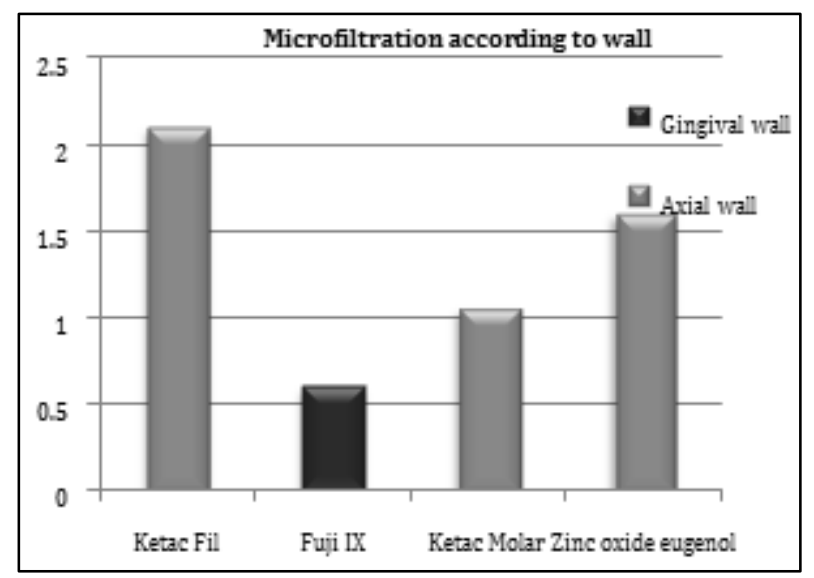

Graph 2. Microfiltration of each material according to wall affected.

\section{Discussion}

The treatment of deep caries lesions presents a challenge to the dentist whose objective should always be conservative. This new therapeutic approach will involve providing time for the repair of pulp and the tooth's defense mechanisms by means of placing adequate materials to protect the pulp, a treatment strategy endorsed by authors such as Conrado et al. [20] and Bjorndal [21].

Different studies vouch for the success of this technique in primary dentition $[9,10]$.A retrospective study by $\mathrm{Al}$ Zayer et al. [11] found that indirect pulp treatment (IPT) of posterior primary teeth is a good alternative to vital pulp therapy. Other studies [9] have concluded that IPT in primary dentition delays the advance of caries regardless of the material used as a liner.

Various materials are have been used for indirect pulp treatment including calcium hydroxide, glass ionomer, or zinc oxide eugenol. Marchi et al. [10] conclude that indirect pulp treatment of primary molars with calcium hydroxide or glass ionomers shows a high success rate. Meanwhile Magnusson and Sundell [17] used zinc oxide eugenol as a temporary restoration material with successful outcomes.

Marchi et al. [10] found no significant differences between the success rates obtained with different materials; even when different techniques were adopted and performed by different clinicians, the success rate of indirect pulp treatment remained at $95 \%$.

In this way, glass ionomer is a much-used restoration material in pediatric dentistry and the favorable longevity of primary dentition restorations has been demonstrated in various clinical studies. Loyola-Rodriguez et al. [22] have shown that all glass ionomer liners show good antibacterial activity against Streptococcus sobrinus and S. mutans, associated with fluoride release. 
At the same time, Gómez-Zebadúa et al. [23] affirm that glass ionomers show good adhesive properties; good adhesion is accompanied by less microleakage, making glass ionomer the material of choice for this type of treatment, a finding that concurs with the results of the present study.

Microleakage is one of the most common causes of failure for most pulp-capping materials, and is always related to the material's adaption to the dental cavity walls and its retention capacity, which determines its ability to seal the cavity and protect it from invasion by oral fluids and microorganisms. If this occurs, it can provoke hypersensitivity of the restored tooth, dental discoloration, recurrent caries, pulp damage and accelerated deterioration of the restoration material. For this reason, it is preferable to use a restoration material with good adhesive properties, which will in turn minimize microleakage and reduce the potential recurrence of caries [25].

The relation between marginal leakage around the restoration and the type of restoration material used has been extensively studied in both laboratory and clinical studies. There are various methods for detecting microleakage that include: organic dyes and stains, chemical and radioactive tracers, electro-microscopy, neutron activation analysis, and fluid filtration. Of these techniques, the most commonly used is the penetration of dyes into sections of the restored tooth [25], as it is a simple, economical and quick technique, and does not require complicated laboratory equipment. The disadvantages of the method arise from the smaller diameter of the marker molecules compared with bacterial toxin molecules and the bacteria itself. Studies that have used this technique have used methylene blue, Indian ink, basic fuchsine, crystal violet, and fluorescein. The present study used the dye technique with methylene blue for measuring microleakage.

In agreement with the present study, others have shown that no restorations performed with glass ionomers are entirely free of microleakage. Numerous trials have compared glass ionomers with resin. Abd El Halim and Zaki [25] observed that nano-ionomers showed less microleakage compared with conventional ionomers.

In an in vivo study, Masih et al. [26] showed that glass ionomers modified with resin underwent more microleakage than conventional ionomers such as Fuji II and Fuji IX. Another study observed that the occlusal marginal seal of glass ionomers that are highly viscous, such as Ketac Molar, is more successful than resin-modified ionomers. However, nano-ionomers showed less or similar microleakage to Ketac Molar at the gingival margin. The fact that occlusal microleakage is greater with nano-ionomers is related to resin content, as this undergoes greater contraction as a result of polymerization [27].

Another issue to consider is the type of cavity preparation required for indirect pulp capping. The present study used Class II cavities for all the ionomers assayed. Koenigsberg et al. [28] stressed the point that Class II obturation involves a higher risk of microleakage than other types of cavity preparation, a fact that must be considered when carrying out indirect pulp treatment.

In the present study, Fuji IX ionomer obtained higher microleakage values for the axial wall than the gingival, while other ionomers showed higher values for the gingival wall. These findings coincide with a study by Abraham et al. [27] in which Fuji IX showed more microleakage on the axial wall which could be due to a lack of adhesion between Fuji IX and the tooth, due to the presence of air bubbles during the placement of the capping material in the cavity.

This finding agrees with other studies that have concluded that cavity preparations with their margins on enamel produce consistently strong adhesion, while adhesion to dentin proved a challenge due to the greater presence of inorganic structure in enamel than dentin [29, 30].

Generally speaking, Fuji IX has shown lower microleakage values. Frankenberger et al. [31] state that Fuji IX hardens more quickly and has high viscosity due to its finer crystal particles, polyacrylic acids of greater molecular weight and a high proportion of powder-to-liquid mix, characteristics that would be responsible for the good marginal seal that Fuji IX produces.

Another important observation of the present study was that the easier the material was to handle, the lower the microleakage, a point that future research should bear in mind.

In studies of microleakage, variations in study protocol such as arrangements for tooth storage, different numbers of thermocycles, or different staining solution immersion times, can all affect the results [32-34]. The present study did not subject samples to thermocycling as the procedure can have severe effects on the samples due to the high temperatures involved, and can alter the results - some studies have indicated that thermocycling can increase microleakage [35].

The present in vitro study did not cover all the variables that affect conditions in the mouth. Further clinical studies are needed to compare and evaluate additional properties of the different materials available for indirect pulp treatment, such as flexural strength, the materials' adherence, hardness, as well as other characteristics such as ease of handling, and working times.

\section{Conclusions}

On the basis of the present results, it may be concluded that glass ionomers (Fuji IX ${ }^{\mathrm{TM}} \mathrm{GP}$ ) are a good option for minimizing microleakage.

Materials that are easier to handle obtain lower levels of 
microleakage.

The ideal material for treating vital pulp must be able to resist bacterial microleakage in the long term and stimulate the remaining pulp to return to a healthy state, promoting dentin formation.

On the basis of the present observations, it is clear that our understanding of the caries process has advanced. This new knowledge demands a change in approaches to treatment that apply valid protocols for the diagnosis and management of dental caries.

\section{REFERENCES}

[1] Fuks AB, CD. Vital Pulp Therapy with New Materials for Primary Teeth: New Directions and Treatment Perspectives. JOE 2008; 34:18-24.

[2] James AC.2008."Indirect Pulp Capping and Primary Teeth: Is the Primary Tooth Pulpotomy Out of Date?'.JOE. 2008. Volumen 34. Número 7S. 34:S34-S39.

[3] James AC, DMD, MS. Indirect pulp capping and primary teeth: is the primary tooth pulpotomy out of date? JOE 2008; 34:34-39.

[4] American Academy of Pediatric Dentistry. Clinical guidelines on pulp therapy for primary and Young permanent teeth: reference manual 2006-07. Pediatr Dent 2006;28:144-8

[5] Fuks AB, CD. Vital Pulp Therapy with New Materials for Primary Teeth: New Directions and Treatment Perspectives. JOE 2008; 34:18-24.

[6] Koenigsberg S, Fuks A, Grajower R. The effect of three filling techniques on marginal leakage around class II composite resin restorations in vitro. Quintessence Int 1989;20:117-21.

[7] Farooq NS, Coll JA, Kuwabara A, Shelton P. Success rates of formocresol pulpotomy and indirect pulp treatment of deep dentinal caries in primary teeth. Pediatr Dent 2000;22:278-86.

[8] Straffon LH, Loos P. The indirect pulp cap: a review and commentary. Isr J Dent Sci 2000;17:7-14.

[9] Falster CA, Araujo FB, Straffon LH, nor JE. Indirect pulp treatment: In vivo outcomes of an adhesive resin system vs calcium hydroxide for protection of the dentin-pulp complex. Pediatr Dent 2002;24:241-8.

[10] Marchi JJ, de Araujo FB, Froner AM, Straffon LH, Nor JE. Indirect pulp capping in the primary dentition: a 4-year follow-up study. J Clin Pediatr Dent 2006;31:68-71.

[11] Al-Zayer MA, Straffon LH, Feigal RJ, Welch KB. Indirect pulp treatment of primary posterior teeth: a retrospective study. Pediatr Dent 2003;25:29-36.

[12] Gruythuysen RJ, Weerheijm KL. Calcium hydroxide pulpotomy with a light-cured, cavity-sealing, material after two years. J Dent Child 1997;64:251-3.

[13] King JB, Crawford JJ, Lindahl RI. Indirect pulp capping: A bacteriologic study of deep carious dentin in human teeth. Oral Surg Oral Med Oral Pathol 1965;21:888-899.

[14] Sawusch RH. Direct and indirect pulp capping two new products. JADA. 1982;104:459-462.

[15] Aponte AJ, Hartsook JH, Crowley M. Indirect pulp capping succes verified. ASDC J Dent Child 1966;33:164-166.

[16] Lars B, DDS, PhD. Indirect Pulp Therapy and Stepwise Excavation. JOE 2008;34:29-33

[17] Magnusson BO, Sundell SO. Stepwise excavation of deep carious lesions in primary molars. J int Assoc Dent Child $1977 ; 8: 36-40$

[18] Salama FS, Riad MI. Abdel Megid FY. Microleakage and marginal gap formation of glass ionomer resin restorations. J Clinic Pediatr Dent 20:31-36, 1995.

[19] Miller MB, Castellanos IR, Vargas MA, Denehy GE. Effect of restorative materials of class II composites. J of Esthet Dent. 1996; 8: 107-113.

[20] Conrado C.A. Remineralization of Carious Dentin. II: In Vivo Microradiographic and Chemical Studies in Human Permanent Teeth Capped with Calcium Hydroxide. Braz Dent J 2004, 15(3): 186-189.

[21] Bjorndal L, Indirect Pulp Therapy and Stepwise Excavation. Journal of Endodontics2008;34:29-33.

[22] Loyola-Rodriguez JP, García-Godoy F, Linquist R. Growth inhibition of glass ionomer cements on mutans streptococci. Pediatr Dent J 1994;16(5):346-9.

[23] Gómez-Zebadúa I, Villalobos-Domínguez E, Arroyo-González G,Andrade-Flores F. Estudio comparativo de la microfiltración con cuatro diferentes recubrimientos pulpares indirectos en molares deciduos. Med Oral. 2000; 2: 102-106.

[24] Shruthi A S, Nagaveni N B, Poornima P, Selvamani M, Madhushankari G S, Subba Reddy V. Comparative evaluation of microleakage of conventional and modifications of glass ionomer cement in primary teeth: An in vitro study. Journal of Indian Society of Pedodontics and Preventive Dentistry 2015; 33:279284.

[25] Abd El Halim S, Zaki D. Comparative evaluation of microleakage among three different glass ionomer types. Operat Dent 2011;36:3642.

[26] Masih S, Thomas AM, Koshy G, Joshi JL. Comparative evaluation of the microleakage of two modified glass ionomer cements on primary molars. An in vivo study. J Indian Soc Pedod and Prev Dent 2011; 29:135 9.

[27] Abraham D, Thomas A M, Chopra S, Koshy S. A Comparative Evaluation of Microleakage of Glass Ionomer Cement and Chitosan-modified Glass Ionomer Cement: An in vitro Study. Int J of Clinic Pediatr Dent 2014;7(1):6-10.

[28] Koenigsberg S, Fuks A, Grajower R. The effect of three filling techniques on marginal leakage around class II composite resin restorations in vitro. Quintessence Int. 1989; 20:117-21.

[29] Swift EJ Jr, Perdigão J, Heymann HO. Bonding to enamel and dentin: A brief history and state of the art, 1995. 
Quintessence Int1995;26:95-110.

[30] Eronat N, Yilmaz E, Kara N, Ak AT. Comparative evaluation of microleakage of nano-filled resin-modified glass ionomer: An in vitro study. Eur J Dent 2014;8:450-5.

[31] Frankenberger R, Sindel J, Kramer N. Viscous glass-ionomer cements: A new alternative to amalgam in the primary dentition? Quintessence Int. 1997 Oct;28(10):667-676.

[32] Litkowski LJ, McDonald NJ, Swierczewski MA. A comparision of the thermocycling methods for evaluatin microleakage. J Dent Res 68: Abstract 208.1989
[33] Gladys S, Van Meerbeek B, Lambrechts P, Vanherle G. Marginal adaptation and retention of a glass-ionomer, resin-modified glass-ionomers and a polyacid-modified resin composite in cervical Class-V lesions. Dent Mater1998;14:294-306.

[34] Rodrigues JA, De Magalhães CS, Serra MC, Rodrigues Júnior AL. In vitro microleakage of glass-ionomer composite resin hybrid materials. Oper Dent 1999; 24: 89-95.

[35] Litkowski LJ, McDonald NJ, Swierczewski MA. A comparision of the thermocycling methods for evaluatin microleakage. J Dent Res 68: Abstract 208.1989. 